\title{
Effects of growth and dissolution on the fractionation of silicon isotopes by estuarine diatoms
}

Xiaole Sun ${ }^{\mathrm{a}^{*}}$, Martin Olofsson ${ }^{\mathrm{b}}$, Per S. Andersson ${ }^{\mathrm{c}}$, Brian Fry ${ }^{\mathrm{d}}$, Catherine Legrand ${ }^{\mathrm{b}}$, Christoph Humborg ${ }^{\text {eff }}$, Carl-Magnus Mörth ${ }^{\text {a,f }}$

${ }^{a}$ Department of Geological Sciences, Stockholm University, SE-10691, Stockholm, Sweden

${ }^{\mathrm{b}}$ Centre for Ecology and Evolution in Microbial model Systems (EEMiS), Faculty of Health and Life Sciences, Linnæus University, SE-39182 Kalmar, Sweden.

${ }^{\mathrm{c}}$ Department of Geosciences, Swedish Museum of Natural History, SE-10405, Stockholm, Sweden

${ }^{\mathrm{d}}$ Australian Rivers Institute, Griffth University, Nathan, QLD 4111 Australia

${ }^{\mathrm{e}}$ Department of Applied Environmental Science, Stockholm University, SE-10691 Stockholm, Sweden

${ }^{\mathrm{f}}$ The Baltic Center, Stockholm University, SE-10691 Stockholm, Sweden

* Corresponding author. Current address: Department of Earth Sciences, the University of Cambridge, CB2 3EQ, Cambridge, UK. Email: xs243@cam.ac.uk 


\begin{abstract}
Studies of silicon $(\mathrm{Si})$ isotope fractionation during diatom growth in open ocean systems have documented lower $\mathrm{Si}$ isotopic values $\left(\delta^{30} \mathrm{Si}\right)$ in the biogenic silica of diatom frustules compared to dissolved silicon. Recent findings also indicate that $\mathrm{Si}$ isotope fractionation occurs during dissolution of diatom frustules, producing higher $\delta^{30} \mathrm{Si}$ values in the remaining biogenic silica. This study focuses on diatoms from high production areas in estuarine and coastal areas that represent approximately 30 to $50 \%$ of the global marine primary production. Two species of diatoms, Thalassiosira baltica and Skeletonema marinoi, were isolated from the brackish Baltic Sea, one of the largest estuarine systems in the world. These species were used for laboratory investigations of $\mathrm{Si}$ isotope fractionation during diatom growth and the subsequent dissolution of the diatom frustules. Both species of diatoms give an identical $\mathrm{Si}$ isotope fractionation factor during growth of $-1.50 \pm 0.36 \%(2 \sigma)$ for ${ }^{30} \mathrm{Si}$, which falls in the range of $-2.09 \sim-0.55 \%$ of published data. Our results also suggest a dissolution-induced $\mathrm{Si}$ isotope fractionation factor of $-0.86 \%$ at early stage of dissolution, but this effect was observed only in DSi and no significant Si isotope change was observed for BSi. The growth and dissolution results are applied to a Baltic Sea sediment core to reconstruct DSi utilization by diatoms, and found to be in agreement with the observed DSi uptake rates in the overlying water column during diatom growth.
\end{abstract}




\section{INTRODUCTION}

Diatoms are important contributors to global carbon fixation and are the world's largest contributors to biosilicification in marine systems (Nelson et al., 1995; Buesseler, 1998). Land-ocean fluxes from rivers contribute approximately $75 \%$ of the total load of dissolved silicon (DSi) and biogenic silica (BSi) to marine systems, of which about $20 \%$ is trapped in estuaries (Treguer and De La Rocha, 2013). Therefore estuaries are a crucial link in the Si cycle between land and open ocean systems. One of the most important characteristics of estuaries is that they are highly dynamic, with strong gradients in water turnover times, salinity, nutrients and primary production. Eutrophication, a major worldwide problem that is caused to a large extent by human activities, is concentrated in and around estuaries and shallow coastal waters (Schelske and Stoermer, 1971; Fisher et al., 1988; Conley et al., 1993). The high input of nutrients derived from land typically results in high diatom activity in estuaries, leading to the removal of DSi from water and a decrease in the DSi flux to open oceans. Hence, estuarine systems in general can be regarded as a sink for soluble silica, especially when water turnover is low and primary productivity is high (Treguer et al., 1995; Treguer and De La Rocha, 2013).

To better assess DSi land-ocean fluxes, it is essential to identify and quantify various biological processes controlling DSi in estuaries. Silicon isotopes in combination with reliable Si isotope fractionation factors can be used as a tool for quantifying these processes. Although large uncertainties are still associated with $\mathrm{Si}$ isotope data due to analytical limits and scarcity of data, detailed Si isotope-based studies of Si dynamics in estuaries will improve our knowledge of the global biogeochemical cycle and better constrain the global Si budget.

Silicon has three stable isotopes, ${ }^{28} \mathrm{Si},{ }^{29} \mathrm{Si}$ and ${ }^{30} \mathrm{Si}$. The Si isotope values are usually expressed in $\delta^{\mathrm{x}} \mathrm{Si}$ values (\%) relative to the standard, NBS 28, and according to Eq.1, where $\mathrm{x}=29$ or 30 :

$$
\delta{ }^{x} \operatorname{Si}(\% 0)=\left(\frac{\left(\frac{{ }^{x} S i}{{ }^{28} S i}\right)_{\text {sample }}}{\left(\frac{{ }^{x} S i}{\left({ }^{28}{ }_{S i}\right.}\right)_{\text {standard }}}-1\right) \times 1000
$$


Diatoms take up ${ }^{28} \mathrm{Si}$ faster than the heavier isotopes, resulting in Si isotope fractionation, which can be used to study past and current changes in DSi utilisation by diatoms in various systems using the Rayleigh model (Fig. 1).

Several recent studies have investigated diatoms and $\mathrm{Si}$ isotopes in the ocean. The $\delta^{30} \mathrm{Si}$ values of DSi in the ocean range from about $+0.5 \%$ to $+3.2 \%$, and corresponding $\delta^{30} \mathrm{Si}$ values of $\mathrm{BSi}$ in diatoms range from $-0.7 \%$ to $+2.6 \%$ o (De $\mathrm{La}$ Rocha et al., 2000; Varela et al., 2004; Cardinal et al., 2005; Reynolds et al., 2006; Beucher et al., 2008; Cao et al., 2012). To link the Si utilization by diatoms to Si isotope values, $\mathrm{Si}$ isotope fractionation factors need to be evaluated quantitatively. For example, De La Rocha et al. (1997) cultured marine diatoms in the laboratory, suggesting $\mathrm{Si}$ isotope fractionation factors $\left({ }^{30} \varepsilon_{\mathrm{BSi} \text {-DSi }}\right)$ averaged $-1.1 \%$ during diatom production and were similar across several species. Field observations from seawater showed a similar, but slightly larger range of ${ }^{30} \varepsilon_{\mathrm{BSi} \text {-DSi }},-0.6 \%$ to $-2.2 \%$ (Varela et al., 2004; Cardinal et al., 2005; Cardinal et al., 2007). Similar studies have been done for freshwater environments. For example, the ${ }^{30} \varepsilon_{\mathrm{BSi}-\mathrm{DSi}}$ during diatom production in freshwater was calculated to be $-1.1 \%$ o during a one-year biweekly monitoring program (Alleman et al., 2005).

These findings have been used to gain insights into oceanic Si cycling (De la Rocha et al., 1998; Reynolds et al., 2006; Beucher et al., 2008; van den Boorn et al., 2010), Si cycling in coastal areas (Cao et al., 2012, Ehlert et al., 2012) and Si cycling in lakes (Street-Perrott et al., 2008, Opfergelt et al., 2011). Although estuarine areas account for less than $10 \%$ of total ocean area but are responsible for $30-50 \%$ of global marine primary production (Field et al., 1998; Dunne et al., 2007), no previous estuarine studies have investigated $\mathrm{Si}$ isotope fractionation during diatom growth and dissolution.

When interpreting Si isotope values in $\mathrm{BSi}$ and $\mathrm{DSi}$, much of our knowledge still comes from assumptions about $\mathrm{Si}$ isotope fractionation factors (Reynolds et al., 2006; Sun et al., 2011). Isotope fractionation patterns may be more diverse than older studies might indicate. For example, a recent study by Sutton et al. (2013) showed evidence of a diatom species-dependent $\mathrm{Si}$ isotope fractionation using seven diatom species isolated from the Southern Ocean. Another recent study by Demarest et al. (2009) observed a Si isotope fractionation factor $\left({ }^{30} \varepsilon_{\mathrm{DSi}-\mathrm{BSi}}\right)$ during dissolution of 0.55\%, enriching the residual BSi in heavier Si isotopes. This indicates that if $\mathrm{Si}$ isotope fractionation during dissolution is not taken into account, relative utilization 
of DSi by diatoms would be significantly overestimated, i.e. dissolution-induced $\delta^{30} \mathrm{Si}$ values of BSi would be higher than and not equivalent to the original signal formed in surface water during DSi uptake.

In summary, either species-dependent or dissolution-induced Si isotope fractionation can affect the $\mathrm{Si}$ isotope signals preserved in diatoms. To aid in the studies of $\mathrm{Si}$ isotope fractionation factors in coastal systems, we analyzed the dynamics of $\mathrm{Si}$ isotope values during diatom growth and dissolution in a laboratorycontrolled setting. The resulting Si fractionation factors were tested on a sedimentary record of BSi sampled from the most northern basin of the Baltic Sea, Bothnian Bay.

\section{MATERIALS AND METHODS}

\subsection{Diatom cultures and experimental setup}

The Baltic Sea in Northern Europe is one of the largest estuarine systems in the world, with a surface area of $377000 \mathrm{~km}^{2}$ and a water volume of $21000 \mathrm{~km}^{3}$. Shallow sills between the North Sea and the Baltic Sea restrict the water exchange leading to a long water residence time of approximately 20 years (Papush et al., 2009). The residence time of DSi is 11.2 years for the entire Baltic Sea (Wulff and Stigebrandt, 1989).

Two species of diatoms, the solitary Thalassiosira baltica (TBTV1) and the chain-forming Skeletonema marinoi (SMTV1), were isolated from one of the Baltic basins, the Gulf of Finland, by the Finnish Environment Institute-SYKE, Helsinki, Finland. The isolates were cultured at the EEMiS Center, Linnæus University, Sweden. The stock cultures were grown in $\mathrm{f} / 2$ medium (Guillard, 1975) prepared from $1 \mu \mathrm{m}$ filtered and autoclaved Baltic seawater (salinity of 7 PSU). The initial Baltic seawater contained approximately $20 \mu \mathrm{mol} \mathrm{L}^{-1} \mathrm{DSi}$. To ensure a reliable diatom biomass and sufficient amount of remaining DSi for Si isotopic analyses, additional DSi was added to the culture medium to reach a final DSi concentration near $60 \mu$ mol $\mathrm{L}^{-1}$. Diatoms were grown at $8-10{ }^{\circ} \mathrm{C}$, under a photon flux of $200-250 \mu \mathrm{mol}$ photons $\mathrm{m}^{-}$ $2 \mathrm{~s}^{-1}$ and a 16/8h light/dark cycle.

When the growth reached the exponential phase, diatom cells were collected by filtering the stock culture through 5-10 $\mu$ m nylon nets. The cells were rinsed four times and re-suspended with silicate-free $\mathrm{f} / 2$ medium to minimise the input of DSi 
from the stock cultures. The cells were inoculated in duplicate into 5 L PET bottles to initial chlorophyll a (Chl a) concentrations of $10 \mu \mathrm{g} \mathrm{Chl} \mathrm{a} \mathrm{L}^{-1}$ for TBTV1 and $7 \mu \mathrm{g}$ $\mathrm{Chl} \mathrm{a} \mathrm{L}^{-1}$ for SMTV1. The culture medium was prepared in the same way as the stock solution and the additional Si was added. After inoculation, the diatom cultures were gently bubbled with sterile air to keep them in suspension until DSi depletion occurred under the same conditions as in the stock culture. The TBTV1 and SMTV1 cultures were monitored daily for 5 and 7 days, respectively, for cell counts, $\mathrm{Chl}$ a and DSi concentrations. The purity and intact status of diatom cells was checked under an optical microscope. No strong diatom dissolution was observed during the experimental growth periods of 4-7 days. Use of sterilized medium and low temperatures also kept active bacteria at a minimum level. The $\mathrm{Chl}$ a concentrations were used as an indicator of diatom growth.

After DSi was nearly depleted to concentrations below $0.5 \mu \mathrm{mol} \mathrm{L}^{-1}$ in the two cultures, the growth experiments were terminated. To measure $\mathrm{Si}$ isotope values during the dissolution of diatom frustules, a fraction of the SMTV1 culture (4 L) was distributed into two $2 \mathrm{~L}$ polycarbonate bottles. The bottles were kept in the dark at 22 $24{ }^{\circ} \mathrm{C}$ for 44 days. The same types of samples taken during the diatom growth experiments also were taken during the dissolution experiments. These samples initially were taken daily, but less frequently after the fifth day until $90 \%$ of the diatom frustules were dissolved. In addition, the $\mathrm{O}_{2}$ concentration was measured regularly during dissolution to ensure that no anoxia occurred, and dissolved oxygen concentrations were never lower than $2 \mathrm{mg} \mathrm{L}^{-1}$.

Duplicate aliquots $(2 \mathrm{ml})$ from each replicate were fixed with acidic Lugol's solution, and cells were counted in an inverted light microscope (Olympus BX50) using a Palmer-Maloney counting chamber. Samples $(2 \times 5-15 \mathrm{ml})$ were filtered (Pall AE/E filters) and extracted with $96 \%$ ethanol, then kept overnight at room temperature for chlorophyll a fluorometric analysis (Jespersen and Christoffersen, 1987). To collect diatom cells, $150-200 \mathrm{ml}$ of water was filtered daily (alternatively twice a day if DSi decreased rapidly) through $0.2 \mu \mathrm{m}$ polyethersulphone membrane filters. One hundred millilitres of the filtrate was immediately analysed for DSi concentration according to Valderrama (1995). The remaining filtrates $(50 \mathrm{ml})$ were kept at $4{ }^{\circ} \mathrm{C}$, and the diatom cells were collected on the filters and freeze-dried prior to preparations for $\mathrm{Si}$ isotope analysis. 


\subsection{Sample preparation prior to $\mathrm{Si}$ isotope analysis}

The method used for BSi digestion was adopted and modified from Ragueneau et al. (2005). Polyethersulphone filters containing 2-7 mg of freeze-dried diatoms were placed into $15 \mathrm{ml}$ polypropylene (PP) tubes. A $5 \mathrm{ml}$ solution of $0.25 \mathrm{~mol} \mathrm{~L}^{-1} \mathrm{NaOH}$ (with a purity of 99\%) was added and the samples were heated in a water bath for 1 hour at $90{ }^{\circ} \mathrm{C}$. After cooling, $\mathrm{HCl}$ was used to stop the digestion by neutralising the pH. Centrifugation was performed at $4200 \mathrm{rpm}$ for 5 minutes to pellet the filters. All the supernatant could be easily transferred to another PP tube and diluted to $10 \mathrm{ml}$ solution for further treatment.

Dissolved $\mathrm{Si}$ in water samples was extracted by a magnesium two-step coprecipitation technique adopted from Reynolds et al. (2006). Two hundred microliters of $1 \mathrm{~mol} \mathrm{~L}^{-1} \mathrm{NaOH}$ was added to $10 \mathrm{ml}$ of the water samples. Samples were shaken and left for 1 hour, then centrifuged at $4200 \mathrm{rpm}$ for 5 minutes. Another $100 \mu \mathrm{l}$ of 1 mol L ${ }^{-1} \mathrm{NaOH}$ was added into the separated supernatant to precipitate more $\mathrm{Mg}(\mathrm{OH})_{2}$. After the samples were shaken and left for another hour, they were centrifuged and the supernatant was removed. The precipitates were then dissolved in $4 \mathrm{~mol} \mathrm{~L}^{-1} \mathrm{HCl}$. The removed supernatant was analysed to make sure the complete Si removal.

The purification of Si from the dissolved diatom solution and water samples was performed using a BioRad AG50W-X12 cation-exchange resin. Five hundred microliters of sample in $0.2 \mathrm{~mol} \mathrm{~L}^{-1} \mathrm{HCl}$ was loaded on the column with a $1 \mathrm{ml}$ resin bed and eluted with $4 \mathrm{ml}$ Milli-Q water. The Si has no charge and therefore passes readily through the resin with Milli-Q water (see detailed information in Sun et al. 2011).

\subsection{Silicon isotope analysis}

The Si isotope compositions of both DSi and BSi were analysed in the Laboratory for Isotope Geology at the Swedish Museum of Natural History, Stockholm, Sweden, using an IsoProbe MC-ICP-MS with a hexapole collision cell. Generally, this instrument is capable of precisely and accurately measuring $\delta^{29} \mathrm{Si}(2 \sigma$, better than $0.2 \%$ ), although measuring $\delta^{30} \mathrm{Si}$ is not possible due to the instrument's low resolution $(\mathrm{m} / \Delta \mathrm{m} \sim 450)$. The instrumental mass discrimination is corrected by applying the standard-sample bracketing technique. The standard, NBS28 was measured five times 
and in between the Si samples were measured four times. Each value reported for each sample in this study is the average value of these measurements. The sensitivity for ${ }^{28} \mathrm{Si}$ is $\sim 12 \mathrm{~V} / 36 \mu \mathrm{mol} \mathrm{L}{ }^{-1} \mathrm{Si}\left(1 \mathrm{mg} \mathrm{L}^{-1}\right)$, with an uptake rate of $\sim 70 \mu \mathrm{min}^{-1}$ via a $\operatorname{Cetac}^{\circledR}$ Aridus desolvating nebuliser. The detailed measurement procedure has been documented in Sun et al. (2010). To show consistency of the measurements and for comparison with data measured by other labs, the long-term reproducibility over four years shown for the standards IRMM-18 and Big Batch is briefly summarized in Table $1 . \delta^{30} \mathrm{Si}$ values are calculated from the relationship $\delta^{30} \mathrm{Si}=\delta^{29} \mathrm{Si} \times 1.96$, which assumes mass-dependent fractionation (Reynolds et al., 2007). Data are reported here as $\delta^{30} \mathrm{Si}$ values.

\subsection{Data reduction and analysis}

The batch experiment was set up in closed containers without replenishing DSi and BSi, giving Rayleigh behaviour in a closed system (Mariotti et al., 1981). This means that a substrate ( $\mathrm{DSi}$ or $\mathrm{BSi}$ ) is continuously removed to form a product (BSi or DSi), but neither undergoes any exchange with an outside system. Silicon isotope values of the substrate and product could be analyzed using the Rayleigh model (Mariotti et al. 1981), expressed by the following equations:

$$
\begin{gathered}
\delta^{30} \mathrm{Si}_{\text {substrate }}=\delta^{30} \mathrm{Si}_{0}+{ }^{30} \varepsilon \times \ln (\mathrm{f}) \\
\delta^{30} \mathrm{Si}_{\text {product }}=\delta^{30} \mathrm{Si}_{0}-{ }^{30} \varepsilon \times \mathrm{f} /[(1-\mathrm{f}) \times \ln (\mathrm{f})]
\end{gathered}
$$

where $\delta^{30} \mathrm{Si}_{\text {substrate, }} \delta^{30} \mathrm{Si}_{\text {product }}$ and $\delta^{30} \mathrm{Si}_{0}$ are $\mathrm{Si}$ isotope values of the substrates, products and initial substrate, respectively; ${ }^{30} \varepsilon$ is the Si isotope fractionation factor, and $\mathrm{f}$ is the fraction of remaining substrate, DSi in our diatom growth experiments. The overall ${ }^{30} \varepsilon$ can be estimated by calculating the slope of a regression line fitted to the measured $\delta^{30} \mathrm{Si}_{\text {substrate }}$ and $\delta^{30} \mathrm{Si}_{\text {product. }}$. By rearranging Eqns. 2 and $3,{ }^{30} \varepsilon$ can be solved separately as shown in Eqns. 4 and 5:

$$
\begin{gathered}
{ }^{30} \varepsilon=\left(\delta^{30} \mathrm{Si}_{\text {substrate }}-\delta^{30} \mathrm{Si}_{0}\right) / \ln (\mathrm{f}) \\
{ }^{30} \varepsilon=-\left(\delta^{30} \mathrm{Si}_{\text {product }}-\delta^{30} \mathrm{Si}_{0}\right) /\{\mathrm{f} /[(1-\mathrm{f}) \times \ln (\mathrm{f})]\}
\end{gathered}
$$

Alternatively, results can be evaluated with equations 4 and 5 in a combined overall estimation of fractionation via linear regression (see Fig. 2 below).

The Rayleigh model is normally used to decribe kinetic isotope fractionation, but isotope-exchange reactions also can cause isotope fractination in a closed system. These reactions can be viewed as a subset of kinetic isotope reactions. In a closed 
system, the back reactions can occur and chemical equilibrium can be achived. Under such circumstances, isotopic equilibrium can also be established (Eq. 6).

$$
\begin{gathered}
\delta^{30} \mathrm{Si}_{\text {substrate }}=\delta^{30} \mathrm{Si}_{0}-{ }^{30} \varepsilon \times \mathrm{f}^{*} \\
\delta^{30} \mathrm{Si}_{\text {product }}=\delta^{30} \mathrm{Si}_{0}+{ }^{30} \varepsilon \times \mathrm{f}^{*}
\end{gathered}
$$

where $\mathrm{f}^{*}$ is the fraction of product formed, DSi in our diatom dissolution experiments.

The total Si amount in this closed system complies with mass conservation since there is no mass transfer in or out of the system boundary. Therefore, mass conservation of $\mathrm{Si}$ isotopes during production and dissolution can be checked using Eq. 8:

$$
\delta^{30} \mathrm{Si}_{0}=\delta^{30} \mathrm{Si}_{\text {substrate }} \times \mathrm{f}+\delta^{30} \mathrm{Si}_{\text {product }} \times(1-\mathrm{f})
$$

Monto Carlo simulations were performed to propogate the uncertainty of the calculated ${ }^{30} \varepsilon$ derived from analytical errors of Si isotope measurements (Robert and Casella, 2004). This allows a random generation of possible results that substitute a range of values based on a probability distribution for any selected factor that has inherent uncertainty, i.e. measured $\delta^{30} \mathrm{Si}$ values in this case. Five to ten thousand of ${ }^{30} \varepsilon$ values were then calculated using different sets of randomly generated values for $\delta^{30} \mathrm{Si}$ assuming a normal distribution. Finally, a probability distribution of possible ${ }^{30} \varepsilon$ values were obtained, from which the $2 \sigma$ errors can be inferred.

\section{RESULTS}

During the growth experiments, $\mathrm{Chl}$ a concentrations increased exponentially for both TBTV1 and SMTV1 (Fig. 2A,C), while the DSi concentrations decreased (Fig. 2B,D). The Chl a levels reached $200 \mu \mathrm{g} \mathrm{L}^{-1}$ for TBTV1 and $550 \mu \mathrm{g} \mathrm{L}^{-1}$ for SMTV1, respectively (Table 2). The DSi concentrations decreased progressively during growth (Fig. 2B, D) and the experiment was terminated when the DSi concentrations fell below $0.4 \mu \mathrm{mol} \mathrm{L}{ }^{-1}$ (Table 2). During exponential growth, the maximum growth rate was 0.42 day $^{-1}$ for TBTV1 and 1.08 day $^{-1}$ for SMTV1.

The two species of diatoms had similar Si isotopic compositions and $\delta^{30} \mathrm{Si}$ values increased during diatom growth both in BSi and in the remaining DSi (Fig. 3, Table 2). The $\mathrm{Si}$ isotope values in the two species varied by more than $1.3 \%$ for $\delta^{30} \mathrm{Si}$, ranging from $+1.2 \%$ up to $+2.6 \%$. The $\delta^{30} \mathrm{Si}$ values in DSi samples increased from $+2.65 \%$ o to $+5.06 \%$. The two species fractionate Si isotopes during their growth, 
producing almost identical ${ }^{30} \varepsilon_{\mathrm{BSi}-\mathrm{DSi}}$ values of $-1.4 \pm 0.33 \%$ and $-1.6 \pm 0.4 \%$ o $(2 \sigma)$, respectively (Fig. 3). A two-sample t-test, assuming equal variance, shows that there is no significant difference between the ${ }^{30} \varepsilon_{\mathrm{BSi}-\mathrm{DSi}}$ values for TBTV1 and SMTV1 ( $\mathrm{p} \leq$ $0.061)$. The calculated overall average ${ }^{30} \varepsilon_{\text {BSi-DSi value is }-1.5 \pm 0.36 \%}(2 \sigma)$, corresponding to an initial difference of $+1.5 \%$ for $\delta^{30} \mathrm{Si}$ between remaining DSi and accumulated BSi.

The mass balance for all isotopes in the growth experiments was checked using Eq. 8. Within error limits, the concentration-weighted sum of the Si isotope values of DSi and BSi, was equal at each time step to the initial $\delta^{30} \mathrm{Si}$ of DSi $(+2.64 \pm 0.15 \%)$ at the beginning of the experiment.

During the dissolution experiment with SMTV1, Chl a concentrations gradually decreased to $267 \mu \mathrm{g} \mathrm{L}^{-1}$, while the DSi concentration increased to $50 \mu \mathrm{mol} \mathrm{L}{ }^{-1}$ for 30 days (i.e. Day 7-30), and remained 50-60 $\mu \mathrm{mol} \mathrm{L} \mathrm{L}^{-1}$ for the last 19 days (i.e. Day 3049, Fig. 4). During the first 20 days (i.e. Day 7-27) in the dark, the siliceous frustules dissolved at a linear rate $\left(\mathrm{r}^{2}=0.9\right)$ and about $75 \%$ of the silica was released back to the medium. After that, another $15 \%$ of BSi dissolved back to the medium so that in total $90 \%$ of BSi was dissolved.

The $\mathrm{Si}$ isotope values of BSi remained almost constant during dissolution, but the DSi values showed significant changes (Fig. 5). The data were analyzed with the assumption of equilibrium isotope effects. Analysis of variance, ANOVA, was performed and showed that the slope of the resulting regression line fitted to $\delta^{30} \mathrm{Si}$ of BSi was $0.12 \pm 0.15$ (95\% confidence interval), not significantly different than zero. For DSi the slope was significantly different than zero, indicating a Si isotope fractionation factor of $-0.86 \%$ at the early stage of dissolution.

\section{DISCUSSION}

\subsection{Mechanism of Si isotope fractionation during diatom growth}

The calculated Si isotope fractionation during the growth of the two estuarine diatom species averaged $-1.5 \%$ and was similar to those documented in other studies. Figure 6 shows a comparison of laboratory culture results for the two species from this study with results from other published culture work. Our $-1.6 \pm 0.4 \%$ result for Thalassiosira baltica is consistant with the ${ }^{30} \varepsilon_{\mathrm{BSi} \text {-DSi }}$ value previously reported for the 
same genus: $-1.1 \pm 0.4 \%$ for Thalassiosira weissflogii (De La Rocha et al., 1997), and also within the large range of -0.72 to $-1.21 \%$ for four other Thalassiosira diatoms (Sutton et al. 2013). The ${ }^{30} \varepsilon_{\mathrm{BSi}-\mathrm{DSi}}$ of $-1.4 \pm 0.33 \%$ o $(2 \sigma)$ measured in this study for Skeletonema marinoi is also in agreement with ${ }^{30} \varepsilon_{\mathrm{BSi}-\mathrm{DSi}}$ of $-1.0 \pm 0.4 \%$ reported for Skeletonema costatum by De La Rocha et al. (1997). It should be noted that our $1.5 \%$ results are slightly different from ${ }^{30} \varepsilon_{\mathrm{BSi}-\mathrm{DSi}}$ of $-2.09 \pm 0.18 \%$ for Chaetoceros brevis, and the ${ }^{30} \varepsilon_{\mathrm{BSi}-\mathrm{DSi}}$ of our two estuarine diatom species is around $1 \%$ lower than ${ }^{30} \varepsilon_{\mathrm{BSi}-\mathrm{DSi}}$ of $-0.54 \pm 0.18 \%$ for Fragilariopsis kerguelensis (Sutton et al. 2013).

Overall, the estuarine results are in the mid-range of results reported for oceanic diatom species.

De La Rocha et al. (1997) reported no change in isotope fractionation in laboratory cultures maintained between 12 and $22^{\circ} \mathrm{C}$. Milligan et al. (2004) cultured diatoms at $20^{\circ} \mathrm{C}$ and Sutton et al. (2013) kept temperatures at $18^{\circ} \mathrm{C}$ and $3{ }^{\circ} \mathrm{C}$. Our results with diatom growth at $8-10{ }^{\circ} \mathrm{C}$ agree with these studies that there is no temperature effect on $\mathrm{Si}$ isotope fractionation during growth.

Our $-1.5 \%$ average estimates are also consistent with estimates from field studies that show a value of $-1.1 \%$ o $\pm 0.4 \%$ o $(2 \sigma)$ for ${ }^{30} \varepsilon_{\mathrm{BSi} \text {-DSi }}$ found in Lake Tanganyika (Alleman et al., 2005), $-1.5 \pm 0.3 \%$ o $(2 \sigma)$ in Antarctic surface water (Varela et al., 2004), and $-1.3 \pm 0.4 \%$ o $(2 \sigma)$ in the Southern Ocean (Cardinal et al., 2007). However, it should be noted that these field values are observations of average ${ }^{30} \varepsilon_{\mathrm{BSi} \text {-DSi }}$ of diatom assemblages where conditions are not as controlled as well as in the laboratory experiments and might be influenced by several non-biological factors. The potential variance of ${ }^{30} \varepsilon_{\mathrm{BSi}-\mathrm{DSi}}$ among diatom species should be taken into consideration, as it is also argued by Fripiat et al. (2012) that current field-based models assuming constant ${ }^{30} \varepsilon_{\mathrm{BSi}-\mathrm{DSi}}$ can fail. Thus, the species composition of diatom assemblages should be considered when we interpret $\mathrm{Si}$ isotope data of diatoms, although in results reported this far, the genera of Thalassiosira and Skeletonema show similar ranges of ${ }^{30} \varepsilon_{\mathrm{BSi}}$-DSi.

A plot of $\delta^{30} \mathrm{Si}$ values as a function of $\mathrm{f}$ values (Fig. 3) shows a very good agreement between the experimental results and the Rayleigh model expressed by Eqs. 2 and 3. This behaviour is typical for kinetic isotope effects (KIEs) in a closed system, i.e., the $\mathrm{Si}$ isotope values vary with f values such that the remaining DSi is enriched in the heavier Si isotopes. The growth rate of diatoms is apparently higher than the rate of dissolution when diatoms are alive. Thus the growth data do not 
indicate equilibrium isotope effects (EIEs), i.e. the rate of the forward reaction, production, is much faster than the rate of the backward reaction, dissolution.

The exact mechanism of $\mathrm{Si}$ isotope fractionation during diatom growth is not easy to elucidate. Dissolved $\mathrm{Si}$ is actively taken up from the environment to diatom cells across cell membrane and then is deposited into biogenic silica, while excess DSi in diatom cells is removed by efflux (Martin- Jézéquel et al, 2000; Hildebrand, 2008). Milligan et al. (2004) suggest that Si isotopic discrimination during diatom growth occurs in the DSi uptake step rather than the polymerization and efflux step. If this were true, however, one might expect that changes in DSi uptake associated with changing temperature or irradiation would result in differing KIEs, i.e. different $\mathrm{Si}$ isotope fractionation factors, but laboratory studies have shown no strong evidence for such effects (De La Rocha et al., 1997; Sutton et al., 2013), or the temperature range over which diatoms grow may not be sufficiently large to detect a measurable effect.

\subsection{Mechanism of $\mathrm{Si}$ isotope fractionation during diatom dissolution}

While the dissolution experiments in our study were similar in principle to those conducted by Demarest et al. (2009), there were major differences in detail between these two experiment setups, as outlined in Table 3. Demarest et al. (2009) showed a non-temperature dependent $\mathrm{Si}$ isotope fractionation factor $\left({ }^{30} \varepsilon_{\mathrm{DSi}-\mathrm{BSi}}\right)$ of $-0.55 \pm 0.1 \%$ $(2 \sigma)$ during dissolution in the ocean water when $10-50 \%$ of BSi was dissolved. Our experiment showed an overall $\mathrm{BSi}^{30} \varepsilon_{\mathrm{DSi}-\mathrm{BSi}}$ isotope effect of $-0.12 \%$ (not significantly different than zero), but a relatively strong isotope effect of -0.86 of ${ }^{30} \varepsilon_{\mathrm{DSi}-\mathrm{BSi}}$ in DSi (Eq. 6 and Fig. 5). In contrast to the growth experiments where we obtained equivalent fractionation estimates for the two BSi and DSi pools, we did not find equivalent fractionation estimates for these two pools in the disslution experiments. This means that the two pools are not really balanced, and $\delta^{30} \mathrm{Si}$ of BSi at the end of the experiment should be much higher than the values we observed if there is a KIE or EIE associated with dissolution. This lack of equivalence led us to consider whether a third Si pool could be involved in the dissolution experiments. Therefore, we hypothesize a third pool, a gel, that forms perhaps around the surface of BSi as an intermediate stage during Si dissolution. Ziegler et al. (2005; p. 4604) have also discussed Si dissolution as involving a gel-like phase that they termed 'destabilized layers of crystal structure'. 
In our experiments, we hypothesize no isotope fractionation during movement of Si from the BSi pool to the gel pool, accounting for the lack of isotope increase in the BSi pool. However, there is fractionation in the liberation of Si from the gel into the DSi pool. We further hypothesize that in order to maintain the observed isotope mass balance between BSi at the start of the experiment and DSi at the end of the experiment, the nature of the gel shifted through the experiment, i.e., it was firmer and isolated in our laboratory procedures with BSi early in the experiment but was more aqueous and isolated mostly with DSi late in the experiment as the solubility of Si gel decreased with the increasing DSi concentration throughout the experiment. This shifting nature of the gel could explain why DSi was initially quite different than BSi (and gel $\mathrm{Si}$ ). At the end of the experiment, the more aqueous gel with higher $\delta^{30} \mathrm{Si}$ values would be more physically similar to DSi with lighter $\delta^{30} \mathrm{Si}$ and these two pools would be mixed together in our laboratory procedures, leading to the convergence of the $\delta^{30} \mathrm{Si}$ values of DSi to the initial value of $+2.55 \%$ (Fig. 5). It is also worth noting that Demarest et al. (2009) kept constant mixing of BSi samples on a shaking table, while we left diatoms in dark without mixing. Lack of disturbance/abrasion may allow the formation of gel Si.

A different explanation might involve more complex re-cycling reactions, especially because we did not specifically kill the diatoms and they may have been marginally active during the extended dark experiment. The survival length of diatoms in dark has been suggested to be species- and temperature-dependent (Smayda and Mitchell-Innes, 1974; Peters, 1996). Skeletonema costatum, the same genera in our experiment, can survive for two weeks or less at temperature of above $20{ }^{\circ} \mathrm{C}$ (Smayda and Mitchell-Innes, 1974), which is the case of our 44-day dissolution experiment conducted at $22-24{ }^{\circ} \mathrm{C}$. Thus, diatom dark growth may have kept the $\delta^{30} \mathrm{Si}$ of BSi from rising strongly at the early/mid stages of dissolution if diatoms were taking up lighter Si isotopes faster during growth. However, it is not likely that a growth-induced KIE is controlling the variations of Si isotope values, because the $\delta^{30} \mathrm{Si}$ values of DSi regenerated at the early stage shows $-0.39 \%$ ower than $\delta^{30} \mathrm{Si}$ values of initial BSi. If this dark growth were important, the $\delta^{30} \mathrm{Si}$ values of DSi should be higher than the $\delta^{30} \mathrm{Si}$ values of BSi, as we observed in the growth experiments (Fig. 3). Observed lower $\delta^{30} \mathrm{Si}$ values of DSi (Fig. 5) points to a KIE or EIE associated with dissolution in the experiment, which is a dominant effect overriding any KIE associated with dark diatom growth. 
Our dissolution experiment started when diatoms were still alive with complete cells, while Demarest et al. (2009) started the dissolution after removing the organic coatings. Active diatom cells with their protective organic coatings may be resistant to dissolution in a medium of undersaturated seawater, especially in the absence of bacteria (Bidle and Azma, 1999; van Cappellen et al. 2002; Bidle et al. 2003). These protective organic coating may have contributed to the smaller ${ }^{30} \mathrm{Si}$ fractionations for BSi observed in this study that Demarest et al. (2009). This also implies that our findings might be more reliable in the surface ocean where diatom cells left intact with their organic coatings, while Demarest et al. (2009) is more applicable to marine sediments where the organic coatings are stripped.

In summary, our results are most consistent with an EIE that does not change $\delta^{30} \mathrm{Si}$ values of BSi during Si dissolution, and thus contrasts to the strong dissolution isotope effects for BSi documented by Demarest et al. (2009). There are many differences between the details of the dissolution experiments (Table 3), and further experiments seem warranted to better understand the reasons for these differences. For example, this study could be repeated using killed diatoms as well as diatoms adapted to grow in the dark. In terms of the complexity of the mechanism behind these biological/physical/chemical processes during diatom growth and dissolution, these kinds of studies are important and could be focused on replicating situations where most dissolution occurs, e.g. slowly in sediments from dead diatoms or quickly in the deeper water column with sinking but inactive cells.

\subsection{Applications of the Si isotope fractionation factor}

Our observation of no significant isotope fractionation during BSi dissolution suggests that the $\mathrm{Si}$ isotope composition of diatoms preserve a direct record of their original environment. We tested this by applying our calculated Si isotope fractionation factor to our measured $\delta^{30} \mathrm{Si}$ values preserved in sedimentary BSi derived from Bothnian Bay, in the most northern part of the Baltic Sea. The long residence time of 3.2 years for DSi in Bothnian Bay allows the assumption of a closed system comparable to our lab experiments (Wulff and Stigebrandt, 1989). A $38 \mathrm{~cm}$ sediment core represents the last 180 years dated by ${ }^{210} \mathrm{~Pb}$ technique. Details about this core can be found in Sun et al. (2011). 
There is a strong biological control on Si isotope values in the Baltic Sea water due to the large proportion of diatoms in the phytoplankton community (Klais et al., 2011). Given a ${ }^{30} \varepsilon_{\mathrm{BSi} \text {-DSi }}$ of $-1.5 \pm 0.36 \%$ for diatom production, it is possible to address the potential range of variations in the Si isotope values in the Baltic Sea. Figure 1 shows the expected behaviour of diatom production following the Rayleigh model and illustrates the possible $\mathrm{Si}$ isotope values in remaining DSi and diatoms determined by the experiments performed in this study. Sun et al. (2011) reported that $\delta^{30} \mathrm{Si}$ values of DSi in rivers draining into Bothnian Bay possibly shifted from $+1.1 \%$ measured in the biggest pristine river (Engström et al., 2010) to $+1.4 \%$ o due to river damming occurring between 1940 and 1970. The values for $\delta^{30} \mathrm{Si}_{0}$ are likely to vary in this range. By using ${ }^{30} \varepsilon_{\mathrm{BSi}-\mathrm{DSi}}$ of $-1.5 \pm 0.36 \%$ and approximately $30 \%$ depletion of DSi in Bothnian Bay (Danielsson et al., 2008), i.e., $f=0.7$, the range of +1.64 $+2.0 \%$ of $\delta^{30} \mathrm{Si}$ in remaining DSi is calculated by Eq. 2. Likewise, $-0.14-+0.16 \%$ of $\delta^{30} \mathrm{Si}_{\text {product }}$ in accumulated BSi is calculated by Eq. 3. Monte Carlo analysis was used to better estimate the uncertainty of this calculation. Five thousand ${ }^{30} \varepsilon_{\mathrm{BSi} \text {-DSi }}$ values were randomly generated assuming a normal distribution based on the average ${ }^{30} \varepsilon_{\mathrm{BSi}}$ DSi of $-1.5 \%$ and its $2 \sigma$ of $0.33 \%$, giving five thousand calculated $\delta^{30} \mathrm{Si}$ values of accumulated BSi with average values of $-0.14 \pm 0.35 \%$ and $+0.16 \%$ o $\pm 0.34 \%$ o $(2 \sigma)$ for the two different $\delta^{30} \mathrm{Si}_{0}$ values for DSi. This range is comparable with our previously reported $\delta^{30} \mathrm{Si}$ values ranging from -0.18 to $+0.58 \%$ in sedimentary BSi (Sun et al., 2011) without statistically significant differences between these values. However, we cannot fully exclude the possibility that dissolution is important since the $\delta^{30} \mathrm{Si}$ value range is larger than ${ }^{30} \varepsilon_{\mathrm{BSi}-\mathrm{DSi}}$ of $-0.55 \%$ suggested by Demarest et al. (2009) for Si isotope fractionation during dissolution. This is not very likely in this case because diatoms have been highly preserved in sediments of Bothnian Bay and it has been shown that diatom production in Bothnian Bay is mainly dependent on the mixed layer depth regulated by temperature in Bothnian Bay in the last 180 years (Sun et al., 2011), resulting in the relatively large variation of $\delta^{30} \mathrm{Si}$ values in BSi.

\section{CONCLUSION}

This study shows that diatom production yields an analytically indistinguishable $\mathrm{Si}$ isotope fractionation factor $\left({ }^{30} \varepsilon_{\mathrm{BSi}-\mathrm{DSi}}\right)$ of $-1.5 \% \pm 0.36 \%(2 \sigma)$ for ${ }^{30} \mathrm{Si}$ for two diatom species, Thalassiosira baltica and Skeletonema marinoi isolated from an 
estuarine system. This is in agreement with previous measurements for the same genera of diatoms. The Si isotope fractionation factor during dissolution of diatom frustules is found not to significantly change the isotopic composition of BSi although there is a significant isotope effect detectable in the isotopic composition of DSi. Estuarine diatoms fractionate $\mathrm{Si}$ isotopes during their formation of BSi like those do in the open ocean. The dissolution study might be expected to be more normal conditions for sinking diatoms and show analytically indistinguishable $\mathrm{Si}$ isotope value changes in BSi. Our dissolution experiments might be more biologically reliable if most BSi dissolves in the water column before being buried into sediment, such as the undersaturated surface seawater, but Demarest et al. (2009) might be more realistic for diatoms dissolving slowly in sediments. Future work is needed to address these issues. 


\section{ACKNOWLEDGEMENTS}

We are grateful to Dr. Anke Kremp for kindly providing the diatom isolates and Mireia Bertos Fortis for assistance in the laboratory and Dr. Eve Arnold for checking English of this manuscript. Funding for diatom cultivation was provided by the Swedish Research Council Formas through the programme ECOCHANGE "Ecosystem dynamics in the Baltic Sea in a changing climate perspective". This is a contribution to the LnU Centre for Ecology and Evolution using Microbial Models Systems (EEMiS). We thank all reviewers for their insightful comments and suggestions. We are also grateful for the funding from the Swedish Research Council (VR-2007-4763). 


\section{REFERENCES}

Alleman L.Y., Cardinal D., Cocquyt, C., Plisnier P.-D., Descy, J.-P., Kimirei I., Sinyinza D., André L. (2005) Silicon isotopic fractionation in Lake Tanganyika and its main Tributaries. J. Gt. Lakes Res. 31, 509-519.

Beucher C.P., Brzezinski M.A., and Jones J.L. (2008) Sources and biological fractionation of Silicon isotopes in the Eastern Equatorial Pacific. Geochim. Cosmochim. Acta 72, 30633073.

Bidle K. D., and Azam F. (1999) Accelerated dissolution of diatom silica by marine bacterial assemblages. Nature, 397, 508-512.

Bidle K. D., Brzezinski M. A., Long R. A., Jones J. L., and Azam F. (2003) Diminished efficiency in the oceanic silica pump caused by bacteria-mediated silica dissolution. Limnol. Oceanogr., 48, 1855-1868.

Buesseler K.O. (1998). The decoupling of production and particulate export in the surface ocean. Global Biogeochem. Cycles 12, 297-310.

Cao Z., Frank M., Dai M., Grasse P., and Ehlert C. (2012) Silicon isotope constraints on sources and utilization of silicic acid in the northern South China Sea. Geochim. Cosmochim. Acta 97, 88-104.

Cardinal D., Alleman L.Y., Dehairs F., Savoye N., Trull T.W. and André L. (2005) Relevance of silicon isotopes to Si-nutrient utilization and Si-source assessment in Antarctic waters. Global Biogeochem. Cycles 19, GB2007.

Cardinal D., Savoye N., Trull T.W., Dehairs F., Kopczynska E.E., Fripiat F., Tison J.-L. and André L. (2007) Silicon isotopes in spring Southern Ocean diatoms: Large zonal changes despite homogeneity among size fractions. Mar. Chem. 106, 46-62.

Conley D.J., Schelske C.L. and Stoermer E.F. (1993) Modification of the biogeochemical cycle of silica with eutrophication. Mar. Ecol. Prog. Ser. 101, 179-192.

Danielsson Papush L., and Rahm L. (2008) Alterations in nutrient limitations -- Scenarios of a changing Baltic Sea. J. Mar. Sys., 73, 263-283.

De La Rocha C.L., Brzezinski M.A. and DeNiro M.J. (1997) Fractionation of silicon isotopes by marine diatoms during biogenic silica formation. Geochim. Cosmochim. Acta 61, 50515056.

De La Rocha C.L., Brzezinski M.A., DeNiro M.J. and Shemesh A. (1998) Silicon-isotope composition of diatoms as an indicator of past oceanic change. Nature 395, 680-683.

De La Rocha C.L., Brzezinski M.A. and DeNiro M.J. (2000) A first look at the distribution of the stable isotopes of silicon in natural waters. Geochim. Cosmochim. Acta 64, 2467-2477. 
Demarest M.S., Brzezinski M.A. and Beucher C.P. (2009) Fractionation of silicon isotopes during biogenic silica dissolution. Geochim. Cosmochim. Acta 73, 5572-5583.

Dunne J. P., Sarmiento J. L., and Gnanadesikan A. (2007) A synthesis of global particle export from the surface ocean and cycling through the ocean interior and on the seafloor. Global Biogeochem. Cycles, 21, GB4006

Ehlert C., Grasse P., Mollier-Vogel E., Böschen T., Franz J., de Souza G.F., Reynolds B.C., Stramma L. and Frank M. (2012) Factors controlling the silicon isotope distribution in waters and surface sediments of the Peruvian coastal upwelling. Geochim. Cosmochim. Acta 99, 128-145.

Engström E., Rodushkin I., Ingri J., Baxter D.C., Ecke F., Österlund H. and Öhlander B. (2010) Temporal isotopic variations of dissolved silicon in a pristine boreal river. Chem. Geol. 271, 142-152.

Field C. B., Behrenfeld M. J., Randerson J. T. and Falkowski P. (1998) Primary Production of the Biosphere: Integrating Terrestrial and Oceanic Components. Science, 281, 237-240.

Fisher T.R., Harding L.W., Stanley D.W., Ward L.G. (1988) Phytoplankton, nutrients, and turbidity in the Chesapeake, Delaware, and Hudson estuaries. Estuar. Coast. Shelf Sci. 27, 61-93.

Fripiat F., Cavagna A.-J., Dehairs F., Brauwere A.d. and Cardinal D. (2012) Processes controlling the Si-isotopic composition in the Southern Ocean and application for paleoceanography. Biogeosciences 9, 2443-2457.

Guillard R.R.L. (1975) Culture of phytoplankton for feeding marine invertebrates, in: M.H, S.W.L.a.C. (Ed.), Culture of Marine Invertebrate Animals. Plenum Press, New York, 2660 .

Hildebrand M. (2008) Diatoms, Biomineralization Processes, and Genomics. Chemical Reviews 108, 4855-4874.

Jespersen A. M. and Christoffersen K. (1987) Measurements of chlorophyll-a from phytoplankton using ethanol as extraction solvent. Archiv fur Hydrobiologie, 109, 44-454

Klais R., Tamminen T., Kremp A., Spilling K. and Olli, K. (2011) Decadal-scale changes of dinoflagellates and diatoms in the anomalous Baltic Sea spring bloom. PLOS ONE 6, e21567. doi:10.1371/journal.pone.0021567

Mariotti A., Germon J.C., Hubert P., Kaiser P., Letolle R., Tardieux A. and Tardieux P. (1981) Experimental determination of nitrogen kinetic isotope fractionation: Some principles; illustration for the denitrification and nitrification processes. Plant Soil 62, 413-430.

Martin-Jézéquel V., Hildebrand, M., and Brzezinski M.A. (2000) Silicon metabolism in diatoms: implications for growth. Journal of Phycology 36, 821-840. 
Milligan A.J., Varela D.E., Brzezinski M.A., Morel F.M.M. (2004) Dynamics of Silicon Metabolism and Silicon Isotopic Discrimination in a Marine Diatom as a Function of pCO2. Limnol. Oceanogr. 49, 322-329.

Nelson D.M., Treguer P., Brzezinski M.A., Leynaert A., and Queguiner B. (1995) Production and dissolution of biogenic silica in the ocean: Revised global estimates, comparison with regional data and relationship to biogenic sedimentation. Global Biogeochem. Cycles $\mathbf{9}$, 359-372.

Opfergelt S., Eiriksdottir E.S., Burton K.W., Einarsson A., Siebert C., Gislason S.R. and Halliday A.N. (2011) Quantifying the impact of freshwater diatom productivity on silicon isotopes and silicon fluxes: Lake Myvatn, Iceland. Earth Planet. Sci. Lett. 305, 73-82.

Papush L., Danielsson A. and Rahm L. (2009) Dissolved silica budget for the Baltic Sea. J. Sea Res. 62, 31-41.

Peters E. (1996) Prolonged darkness and diatom mortality: II. Marine temperate species. Journal of Experimental Marine Biology and Ecology 207, 43-58.

Ragueneau O., Savoye N., Del Amo Y., Cotten J., Tardiveau B. and Leynaert A. (2005) A new method for the measurement of biogenic silica in suspended matter of coastal waters: using Si:Al ratios to correct for the mineral interference. Cont. Shelf Res. 25, 697-710.

Reynolds B.C., Aggarwal J., André L., Baxter D., Beucher C., Brzezinski M.A., Engström E., Georg R.B., Land M., Leng M.J., Opfergelt S., Rodushkin I., Sloane H.J., van den Boorn S.H.J.M., Vroon P.Z. and Cardinal D. (2007) An inter-laboratory comparison of Si isotope reference materials. J. Anal. At. Spectrom 22, 561-568.

Reynolds B.C., Frank M., and Halliday A.N. (2006) Silicon isotope fractionation during nutrient utilization in the North Pacific. Earth Planet. Sci. Lett. 244, 431-443.

Robert, C. P. and Casella, G. (2004) Monte Carlo Statistical Methods, 2nd ed. Springer, New York. MR2080278

Schelske C.L. and Stoermer E.F. (1971) Eutrophication, silica depletion, and predicted changes in algal quality in Lake Michigan. Science 173, 423-424.

Smayda T.J. and Mitchell-Innes B. (1974) Dark survival of autotrophic, planktonic marine diatoms. Marine Biology 25, 195-202.

Street-Perrott F.A., Barker P.A., Leng M.J., Sloane H.J., Wooller M.J., Ficken K.J. and Swain D.L. (2008) Towards an understanding of late Quaternary variations in the continental biogeochemical cycle of silicon: multi-isotope and sediment-flux data for Lake Rutundu, Mt Kenya, East Africa, since 38 ka BP. Journal of Quaternary Science 23, 375-387.

Sun X., Andersson P., Humborg C., Gustafsson B., Conley D.J., Crill P. and Mörth C.M. (2011) Climate dependent diatom production is preserved in biogenic Si isotope signatures. Biogeosciences 8, 3491-3499. 
Sun X., Andersson P., Land M., Humborg C. and Mörth C.-M. (2010) Stable silicon isotope analysis on nanomole quantities using MC-ICP-MS with a hexapole gas-collision cell. $J$. Anal. At. Spectrom. 25, 156-162.

Sutton J.N., Varela D.E., Brzezinski M.A. and Beucher C.P. (2013) Species-dependent silicon isotope fractionation by marine diatoms. Geochim. Cosmochim. Acta 104, 300-309.

Tréguer P., Nelson D.M., Van Bennekom A.J., DeMaster D.J., Leynaert A. and Queguiner, B. (1995) The Silica Balance in the World Ocean: A Reestimate. Science 268, 375-379.

Tréguer P.J. and De La Rocha C.L. (2013) The World Ocean Silica Cycle. Annual Review of Marine Science 5, 477-501.

Valderama J. C. (1995) Methods of nutrient analysis. In: Hallegraef G. M., Andersson, D. M., Cembella, A. D. (Eds), Manual of Harmful Marine Microalgae, Manuals and Guides No. 33. Intergovernmental Oceanographic Commission of UNESCO. 251 - 268.

Van Cappellen, P., Dixit, S. and van Beusekom, J., 2002. Biogenic silica dissolution in the oceans: Reconciling experimental and field-based dissolution rates. Global biogeochemical cycles, 16, 1075, doi:10.1029/2001GB001431.

van den Boorn, S.H.J.M., van Bergen, M.J., Vroon, P.Z., de Vries, S.T. and Nijman, W., 2010. Silicon isotope and trace element constraints on the origin of $\sim 3.5$ Ga cherts: Implications for Early Archaean marine environments. Geochimica et Cosmochimica Acta, 74(3): 10771103.

Varela D.E., Pride C.J. and Brzezinski M.A. (2004) Biological fractionation of silicon isotopes in Southern Ocean surface waters. Global Biogeochem. Cycles 18, GB1047.

Wulff F. and Stigebrandt A. (1989) A time-dependent budget model for nutrients in the Baltic Sea. Global Biogeochem. Cycles 3, 63-78.

Ziegler K., Chadwick O.A., Brzezinski M.A., Kelly E.F. (2005) Natural variations of $\delta^{30} \mathrm{Si}$ ratios during progressive basalt weathering, Hawaiian Islands. Geochim. Cosmochim. Acta 69, 4597-4610. 
1 Table 1

2 Summary of measurements of Si standards by MC-ICP-MS employed in this study between 2008 and 2012 in comparison to other published data

\begin{tabular}{cccc}
\hline \hline Standard & $\boldsymbol{\delta}^{\mathbf{2 9}} \mathbf{S i}$ & $\mathbf{2 \sigma}$ & $\mathbf{n}$ \\
\hline IRMM-18 & -0.93 & 0.16 & 48 \\
IRMM-18 & -0.85 & 0.14 & 740 \\
Big Batch $^{\text {a }}$ & -5.44 & 0.25 & 10 \\
Big Batch $^{\text {a }}$ & -5.35 & 0.30 & 198 \\
\hline \hline
\end{tabular}


Table 2

Summary of Si concentrations and Si isotope values of DSi and BSi during S. marinoi and T. baltica production and dissolution, as well as the fractionation factor $(\varepsilon)$ calculated by Eq. 4 and 5. $2 \sigma$ of the calculated $\alpha$ is shown below the average values. During production, $f$ values are the fraction of remaining DSi; during dissolution, $f$ values are the fraction of remaining BSi.

\begin{tabular}{|c|c|c|c|c|c|c|c|c|c|c|c|}
\hline Days & $\begin{array}{l}\text { Chl a } \\
\left(\mu \mathrm{g} \mathrm{L}^{-1}\right)\end{array}$ & $\begin{array}{l}\text { DSi conc. } \\
\left(\mu \mathrm{mol} \mathrm{L}^{-1}\right)\end{array}$ & $\mathbf{f}$ & $\delta{ }^{29} \mathrm{Si}_{\mathrm{BSi}}$ & $2 \sigma$ & $\delta{ }^{30} \mathbf{S i}_{\mathrm{BSi}}$ & $\delta^{29} \mathrm{Si}{ }_{\mathrm{DSi}}$ & $2 \sigma$ & $\delta^{30} \mathbf{S i}_{\mathrm{DSi}}$ & $\begin{array}{c}{ }^{29} \boldsymbol{\varepsilon}_{\mathrm{BSi}-\mathrm{DSi}} \\
\mathbf{b y ~ E q . ~} 5\end{array}$ & $\begin{array}{c}{ }^{30} \boldsymbol{\varepsilon}_{\mathrm{BSi}-\mathrm{DSi}} \\
\text { by Eq. } 5\end{array}$ \\
\hline \multicolumn{12}{|c|}{ SMTV1 production } \\
\hline 0 & 6.8 & 64.8 & 1.00 & +0.63 & 0.25 & +1.23 & +1.35 & 0.15 & +2.65 & N/A & N/A \\
\hline 2 & 25.7 & 57.8 & 0.89 & +0.69 & 0.15 & +1.35 & +1.52 & 0.13 & +2.98 & -0.70 & -1.37 \\
\hline 3 & 73.3 & 42.1 & 0.65 & +0.80 & 0.14 & +1.57 & +1.56 & 0.13 & +3.06 & -0.69 & -1.34 \\
\hline 3.5 & 145.3 & 34.3 & 0.53 & +0.86 & 0.24 & +1.69 & +1.81 & 0.10 & +3.55 & -0.68 & -1.34 \\
\hline 4 & 305.0 & 0.4 & 0.01 & +1.32 & 0.09 & +2.59 & N/A & N/A & N/A & -0.64 & -1.26 \\
\hline 5 & 527.7 & 0.4 & 0.01 & +1.31 & 0.10 & +2.57 & N/A & N/A & N/A & -0.86 & -1.69 \\
\hline Average & & & & & & & & & & -0.72 & -1.40 \\
\hline $2 \sigma$ & & & & & & & & & & 0.17 & 0.33 \\
\hline \multicolumn{12}{|c|}{ SMTV1 dissolution } \\
\hline 7 & 550.1 & 0.8 & 0.99 & +1.29 & 0.18 & +2.53 & N/A & N/A & N/A & N/A & N/A \\
\hline 9 & 527.6 & 2.5 & 0.96 & +1.30 & 0.22 & +2.55 & N/A & N/A & N/A & N/A & N/A \\
\hline 12 & 542.5 & 3.6 & 0.98 & +1.30 & 0.10 & +2.54 & N/A & N/A & N/A & N/A & N/A \\
\hline 17 & 499.3 & 8.8 & 0.86 & +1.29 & 0.09 & +2.53 & N/A & N/A & N/A & N/A & N/A \\
\hline 22 & 501.9 & 20.9 & 0.68 & +1.34 & 0.19 & +2.63 & +1.10 & 0.25 & +2.16 & -0.20 & -0.39 \\
\hline 28 & 467.4 & 36.0 & 0.45 & +1.27 & 0.12 & +2.48 & +1.14 & 0.13 & +2.23 & -0.16 & -0.32 \\
\hline 32 & 448.1 & 47.6 & 0.27 & +1.32 & 0.07 & +2.59 & +1.23 & 0.15 & +2.41 & -0.07 & -0.13 \\
\hline 43 & 298.3 & 48.5 & 0.25 & +1.37 & 0.14 & +2.69 & +1.35 & 0.14 & +2.65 & +0.08 & +0.16 \\
\hline 49 & 270.6 & 58.6 & 0.10 & +1.36 & 0.18 & +2.66 & +1.32 & 0.10 & +2.59 & -0.04 & +0.09 \\
\hline Average & & & & & & & & & & -0.06 & -0.12 \\
\hline $2 \sigma$ & & & & & & & & & & 0.25 & 0.40 \\
\hline
\end{tabular}

TBTV1 production 


$\begin{array}{ccccccccccccc}0 & 11.9 & 81.8 & 1.00 & +0.61 & 0.07 & +1.19 & +1.35 & 0.15 & +2.64 & \text { N/A } & \text { N/A } & 4 \\ 1 & 15.3 & 75.2 & 0.92 & +0.64 & 0.19 & +1.25 & +1.43 & 0.11 & +2.81 & -0.74 & -1.45 & 6 \\ 2 & 26.2 & 67.2 & 0.82 & +0.67 & 0.11 & +1.31 & +1.45 & 0.16 & +2.84 & -0.75 & -1.47 & 7 \\ 3 & 42.2 & 58.7 & 0.72 & +0.65 & 0.14 & +1.27 & +1.55 & 0.14 & +3.03 & -0.83 & -1.62 & 8 \\ 3.5 & 43.1 & 54.3 & 0.66 & +0.70 & 0.13 & +1.36 & +1.74 & 0.09 & +3.40 & -0.81 & -1.58 & 9 \\ 4 & 65.0 & 46.8 & 0.57 & +0.84 & 0.13 & +1.65 & +1.66 & 0.13 & +3.25 & -0.68 & -1.3311 \\ 4.5 & 69.2 & 42.3 & 0.52 & +0.74 & 0.17 & +1.46 & +1.80 & 0.07 & +3.52 & -0.86 & -1.6912 \\ 5 & 109.1 & 26.4 & 0.32 & +0.79 & 0.19 & +1.54 & +2.58 & 0.13 & +5.07 & -1.04 & -2.05 & 13 \\ 5.5 & 118.4 & 19.6 & 0.24 & +1.02 & 0.12 & +1.99 & +2.46 & 0.13 & +4.83 & -0.73 & -1.4515 \\ 6 & 133.1 & 2.9 & 0.04 & +1.24 & 0.24 & +2.43 & \text { N/A } & \text { N/A } & \text { N/A } & -0.82 & -1.6116 \\ 7 & 204.3 & 0.3 & 0.004 & +1.33 & 0.16 & +2.60 & \text { N/A } & \text { N/A } & \text { N/A } & -0.90 & -1.77 & 17 \\ 18 \\ \text { Average } & & & & & & & & & & -\mathbf{0 . 8 2} & \mathbf{- 1 . 6 0} 19 \\ 2 \sigma & & & & & & & & & \mathbf{0 . 2 1} & \mathbf{0 . 4 0} 20 \\ 21\end{array}$


27 Table 3 Comparison of two dissolution experiment setups between this study and Demarest et al. (2009)

\begin{tabular}{lll}
\hline \hline & This study & Demarest et al. (2009) \\
\hline Source of diatoms & The Baltic Sea (estuarine areas) & The Southern Ocean (open oceans) \\
Diatom & Skeletonema marinoi & the genus: Chaetoceros \\
$\mathrm{pH}$ & 7 & N/A \\
Salinity & $7 \mathrm{psu}$ & $35 \mathrm{psu}($ average value for ocean water) \\
Temperature & $22 \sim 24^{\circ} \mathrm{C}$ & $3 \sim 20{ }^{\circ} \mathrm{C}$ \\
Pre-treatment of diatoms & None, start with living diatoms & organic coatings outside the BSi layer removed \\
Length of experiment & 44 days & 60 days \\
Percentage of dissolution & Up to $90 \%$ & Up to $60 \%$ \\
Observed ${ }^{30} \varepsilon_{\mathrm{DSi}-\mathrm{BSi}}$ & $-0.12 \pm 0.4 \% \mathrm{o}(2 \sigma)$ with $-0.86 \%$ at & $-0.55 \pm 0.1 \% 0(2 \sigma)$ \\
\hline \hline
\end{tabular}


31 Figure 1 The Rayleigh model of $\mathrm{Si}$ isotopes during diatom production. The lines track the

$\delta^{30} \mathrm{Si}$ values of $\mathrm{BSi}$ and DSi during uptake (DSi) and formation (BSi). As the fraction of DSi remaining in solution (f) decreases, the $\delta^{30} \mathrm{Si}$ values of DSi (the solid line) and accmulated BSi increases (long dashed line). The BSi represents diatoms that accumulates in the system and can never have a $\delta^{30} \mathrm{Si}$ value greater than that of the initial DSi. The $\delta^{30} \mathrm{Si}$ values of BSi instantly produced in time (the short dashed line) is always lower than the $\delta^{30} \mathrm{Si}$ of DSi. This difference is defined as the Si isotope fractionation factor $\left({ }^{\mathbf{x}} \boldsymbol{\varepsilon}_{\mathrm{BSi}} \mathrm{DSi}\right.$, where $\mathrm{x}=29$ or 30 )

Figure 2. A. Chl a concentrations and $\delta^{30} \mathrm{Si}$ values of BSi during growth of SMTV 1. B. DSi concentrations and the $\delta^{30} \mathrm{Si}$ values of DSi for the SMTV 1 culture. C. As panel A, but for TBTV 1. D. As panel A, but for TBTV 1. Error bars for $\delta^{30} \mathrm{Si}$ values are $2 \sigma$.

Figure $3 \mathrm{Si}$ isotope values of diatoms and DSi during diatom growth as a function of $\mathrm{f}$ values (fraction of remaining DSi in water). Lines are calculated for the Rayleigh fractionation model expressed by Eq. 2 and 3 in a closed system. Error bars for Si isotope values are $2 \sigma$. A is for TBTV1; B is for SMTV1, ${ }^{30} \varepsilon_{\mathrm{BSi} \text {-DSi }}$ for each species is the slope of the best-fit linear line for remaining DSi and produced BSi.

Figure 4. A. Changes of $\mathrm{Chl}$ a and $\delta^{30} \mathrm{Si}$ values of BSi of SMTV 1 during diatom dissolution. B. Changes of DSi concentrations and $\delta^{30}$ Si values of DSi during the dissolution period.

Figure 5. $\delta^{30} \mathrm{Si}$ values of BSi (filled circles) and DSi (open circles) and their linear regression equations and lines expected for EIEs during dissolution. The dashed line and its equation shows the isotope trajectory expected for a KIE (-0.58\%o) for accumulating DSi. $f$ for KIE and $f^{*}$ for EIEs is the fraction of regenerated DSi during dissolution. 
59 Figure 6. Comparison of $\mathrm{Si}$ isotope fractionation factor $\left({ }^{30} \varepsilon_{\mathrm{BSi}-\mathrm{DSi}}\right)$ during diatom growth 60 in this study with values published by De La Rocha et al. (1997), Milligan et al. (2004) 61 and Sutton et al. (2013). 


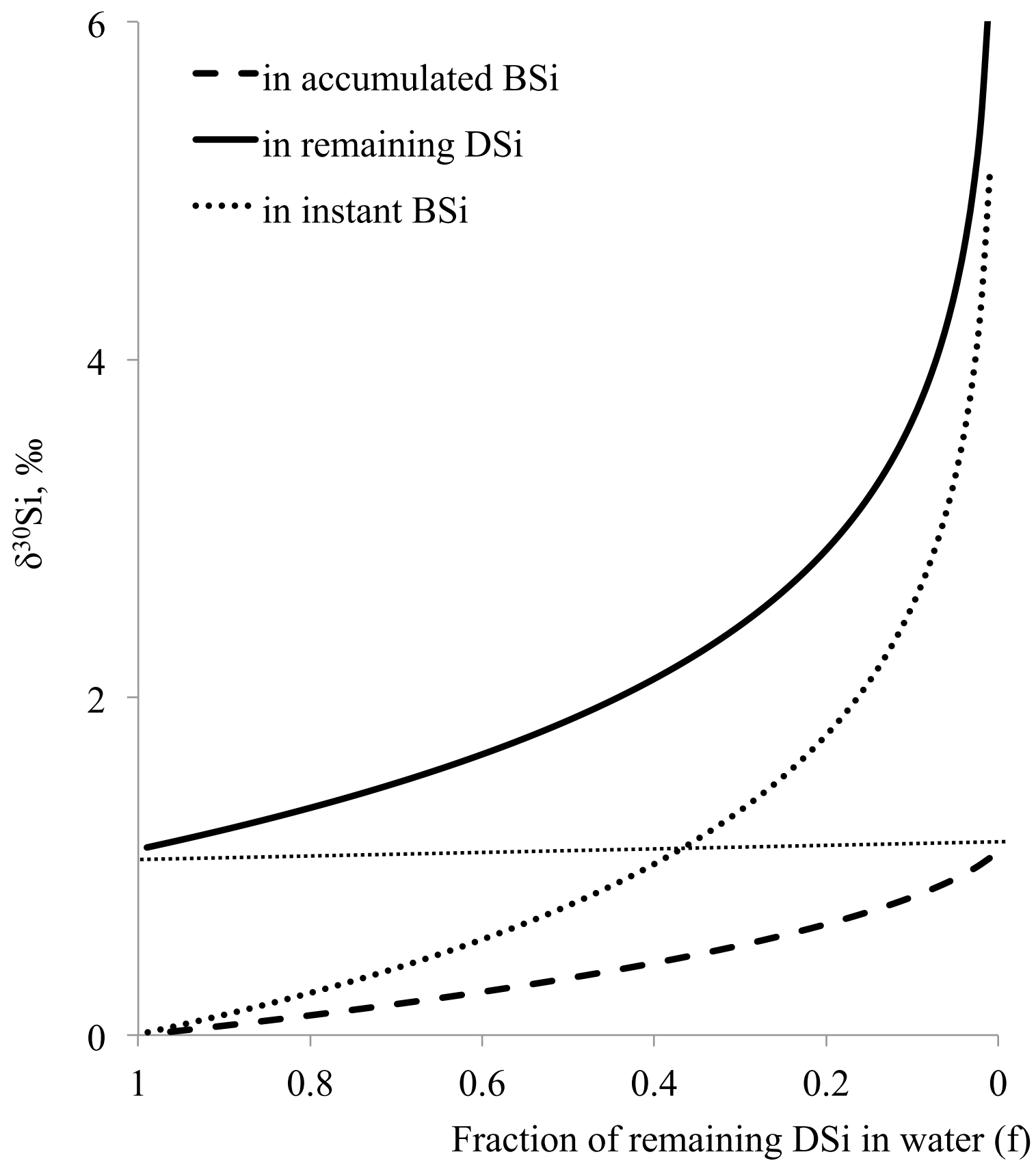

Figure 1 


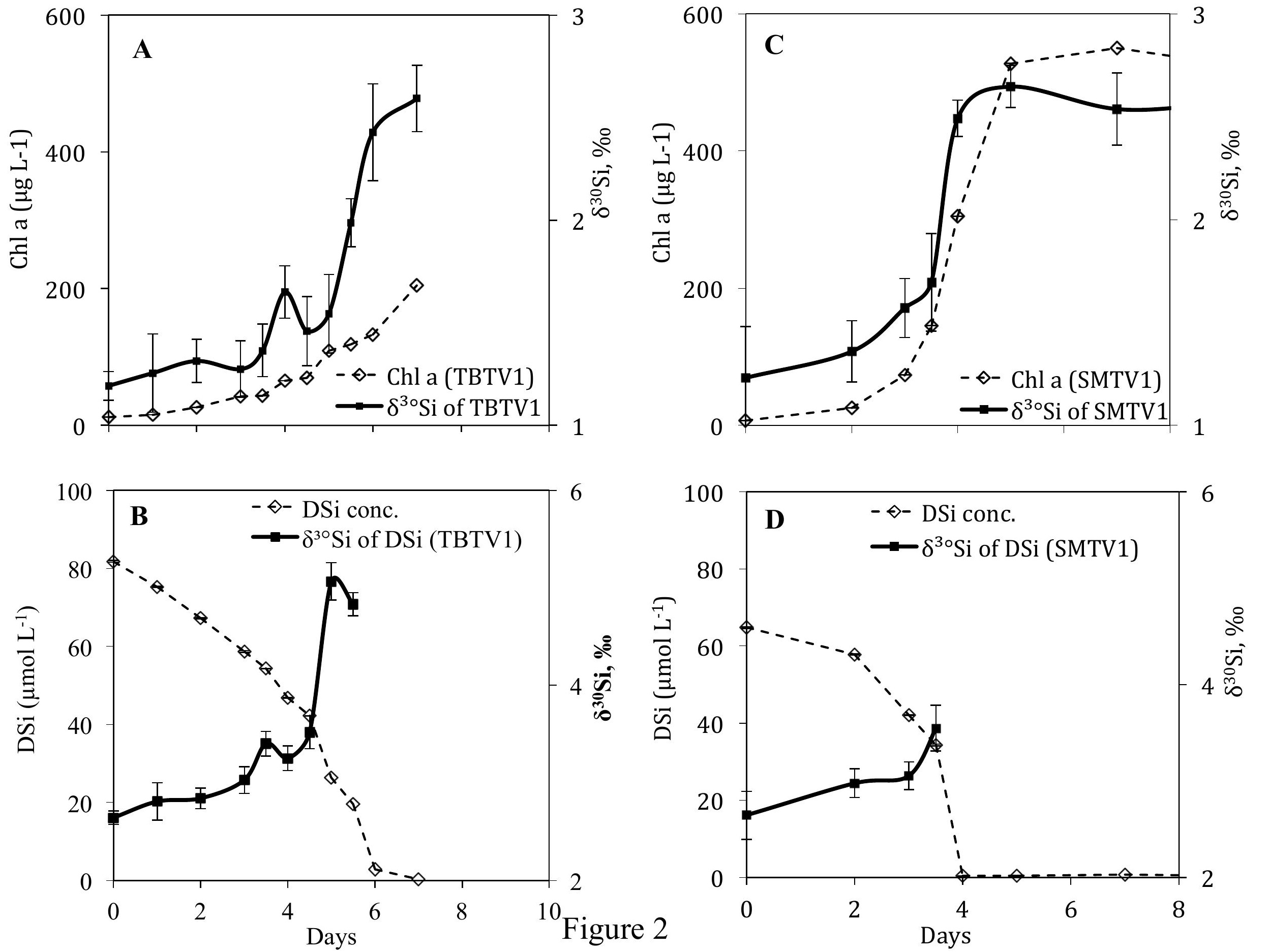




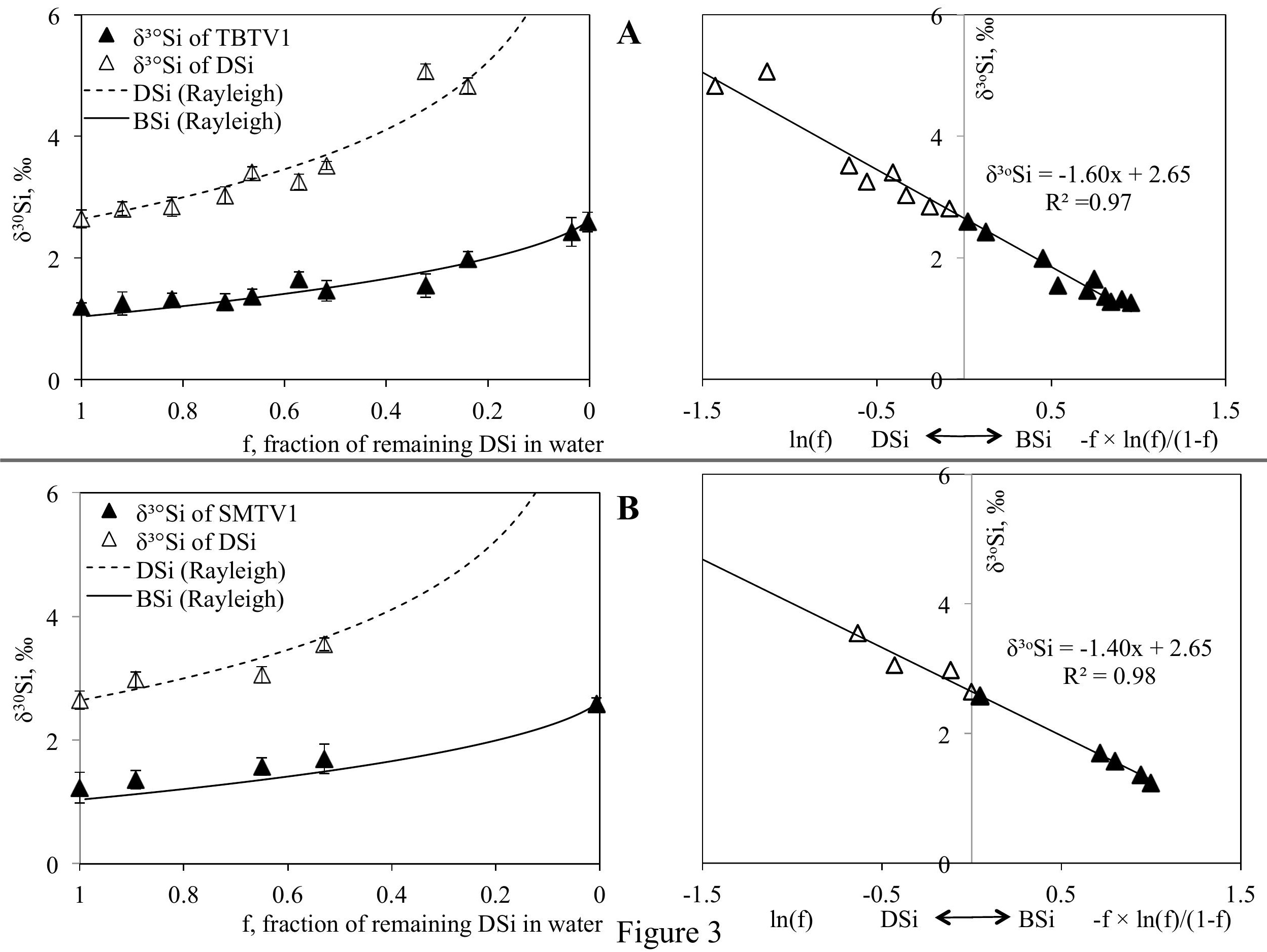




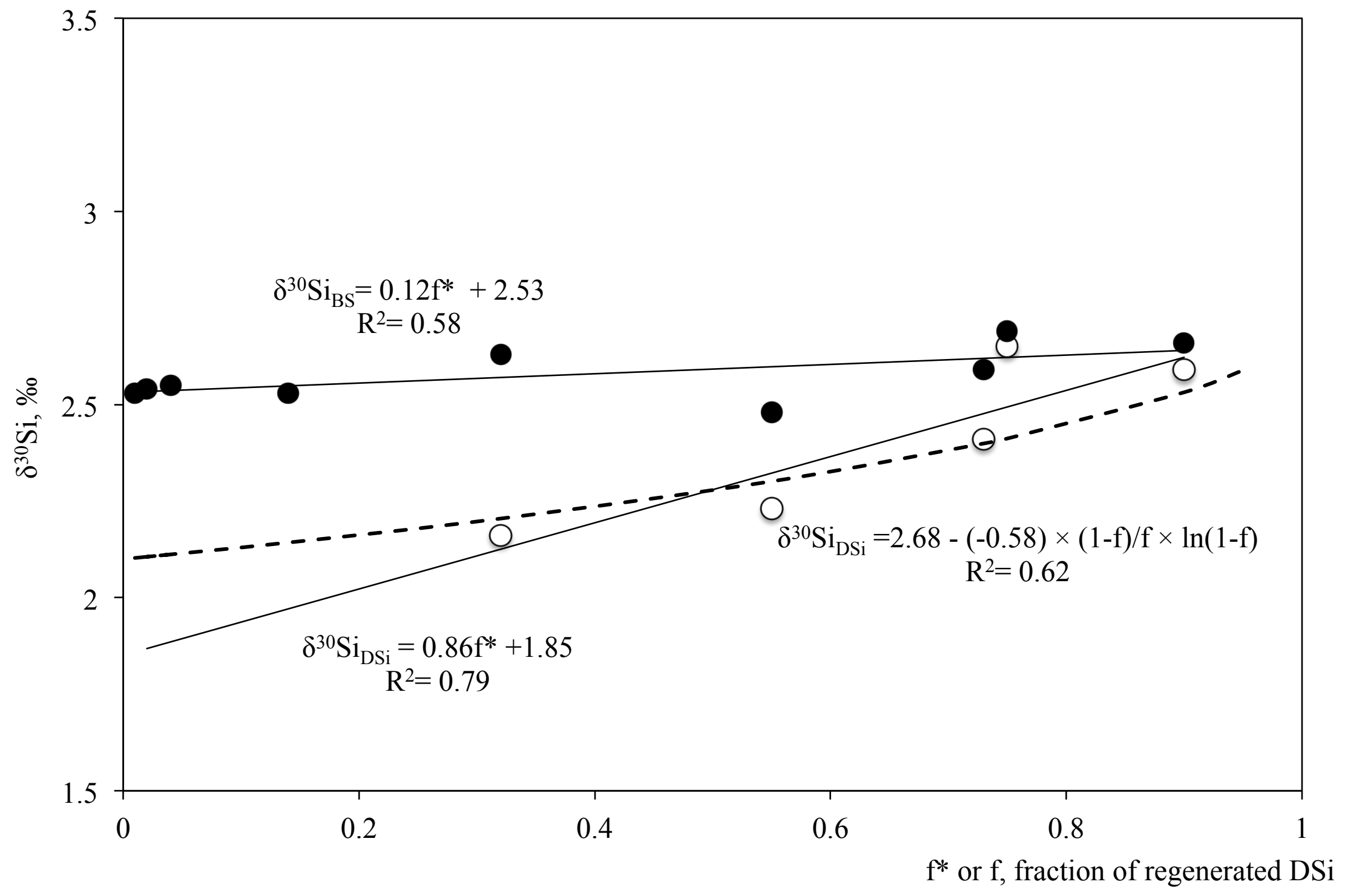

Figure 5 


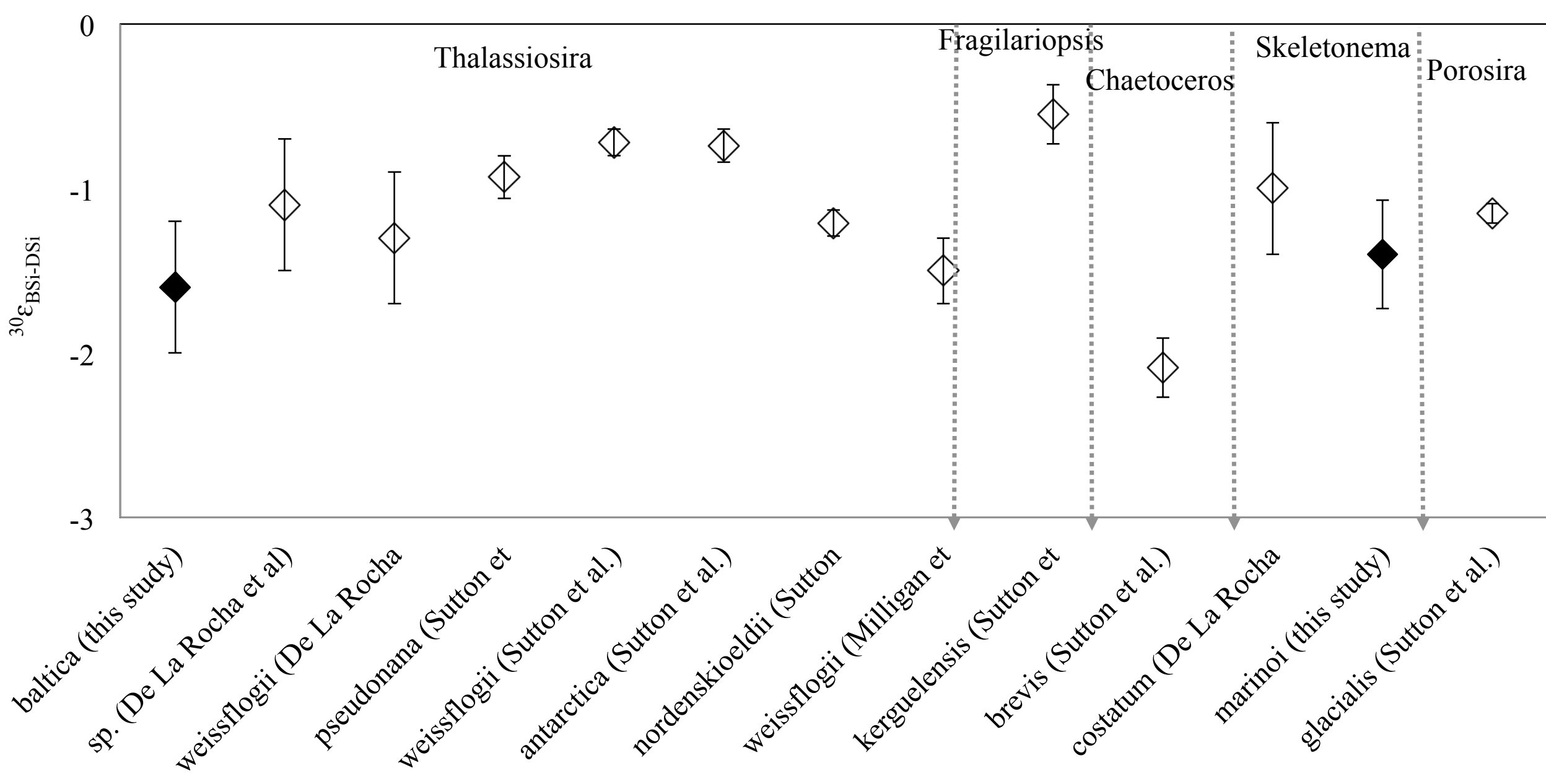

Figure 6 